\title{
Mocidade acadêmica
}

\author{
Luis F. Leite
}

\begin{abstract}
Discurso proferido na comemoração da fundaçâo dos cursos juridicos brasileiros, realizada pelo Centro Academico "XI de Agosto" a 11 de Agosto de 1934, no salão nobre da Faculdade de Direito de São Paulo.
\end{abstract}

Ilustrados membros da Congregação da Faculdade de Direito de S. Paulo.

Prezados colegas da diretoria do Centro XI de Agosto. Minhas Senhoras.

Senhorinhas.

Colegas.

Na data de hoje mais um âno se vem juntar ao século de vida da nossa Escola. Mais um aniversário do Centro XI de Agosto também se comemora hoje. Este e aquela, nêste dia, param um minuto na sua carreira. Plantam um marco anunciador de mais uma vitória. $E$, volvendo a vista para o passado, procuram, nos fastos que se emaranham no amontoado do tempo, novas forças para o muito que ainda têm de caminhar. Animam-se de novo. Olham depois para a frente. Empertigam o corpo que o cansaço vai fazendo curvar-se. E quando o tempo impele de novo os ponteiros que se colaram sôbre um número para que soasse a hora de mais essa vitória, êles enchem-se novamente de esperança e se põem outra vez a marchar gloriosamente para o além. 
Nêste momento, senhores, os ponteiros do tempo se uniram para que batesse essa hora. Reboam pelos ângulos vetustos do velho convento franciscano os sons plangentes de sinos seculares.

E' a hora da Academia. Silêncio, moços estudantes. Êste momento não vos pertence. Hoje, as anosas arcadas voltam para o passado.

Uma legião de sombras começa a se mover. Vêde. 0 ambiente não é o mesmo. A iluminação também não é a de hoje. Perdeu o fulgor dos fócos eletricos para bruxolear na luz pálida dos românticos lampeões. $O$ casario também é outro. Achaparrado e feio, deita para as ruas coleantes os largos beirais. E o São Paulo solarengo que se foi. E o São Paulo das rótulas e das mantilhas. Dos fidalgotes empenados e idas pálidas donzelas. É um outro S. Paulo.

Primeiramente, dorme no largo o convento da ordem franciscana. Os monges, pacatamente, nêle se aninham. Nada há que lhes venha turbar a monotonia de uma santa paz.

Mais tarde começam a ecoar por aqui os protestos dos moços brasileiros que estudanteavam então pela vélha escola coimbrã. São protestos sentidos de uma nova gente espesinhada no seu orgulho.

E daí por diante se agita a opinião dos nossos meios oficiais e intelectuais, no sentido da criação de uma Universidade brasileira. Várias vezes a questão foi abordada. E é interessante lerem-se os debates que se travaram. Os primeiros dêles vieram esbarrar no romântico despotismo do estouvado Pedro I.

Mas não se esgotou a paciência dos que pleiteavam a criação dos cursos superiores brasileiros. Mais projetos vieram. Discussões e mais discusisões, até que, quando na pasta dos negócios da instrução o Visconde de S. Leopoldo, baixou-se a lei de 11 de Agosto de 1827, que criava as atuais Esoolas de Direito de São Paulo e do Recife.

Logo depois da independência política, lançava-se a base da independência intelectual. 
E começa a viver a vélha Academia.

Era como uma célula que nascesse da antíga célula portuguêsa de Coimbra. Quase tudo dela importámos. Orientação, programas. Os lentes, se não haviam nascido em Portugal, tinham cultura toda ela portuguêsa. Fomos, nêsse princípio, pode-se dizer, um prolongamento, nas terras quase virgenis da América, do pensamento europeu. Nada ainda se nos mostrava no colorido dos borrões verdes e amarelos.

Entretanto, a célula vai crescendo. Toma caracteristicas próprias. Deixa de receber, daquela de que proveio, o elemento vitalizador. $\mathrm{E}$ passa a ser o núcleo irradiador de novas formações.

A pouco e pouco vai-se formando no bojo da Academia uma outra conciência. E ella passa a marcar hora a hora, minuto a minuto, o pulsar da nacionalidade. Nela se vêm refletir todas as ansiedades e todas as aspirações do jovem povo. Torna-se o coração de sua gente. Coração que exulta na alegria e sangra nas múltiplas horas de sua angústia.

Dêsde então, as gerações de moços vêm plantando pelo caminho, que hoje vemos sumir-se nas brumas de um passado tão longínquo, os marcos anunciadores de sua vida. São grandes, gigantes. Erguem-se nas várias caudais de sua torrente. São poetas, políticos, juristas.

Para os poetas, principalmente, nós temos sempre na memória um lugar para os seus versos e nos corações um lugar para as suas pessôas. Pululam em legiões no passado acadêmico. Um ou outro se alteia mais, entretanto. E, ou porque se impuzessem pela eloqüência dos seus versos, ou porque afinassem as cordas da sua lira pelas da alma lírica dos moços, colocam-se como senhores absolutos da nossa admiração.

Qual de vós, colegas meus, não terá, para recitar nas horas de melancolia, um verso do pálido Alvares de Azevedo? Que mdeixará de pensar na figura doentia daquela criança, quando as contingências da vida tocam-nois as cordas sensíveis do sentimento? Parece até que os seus versos vivem no 
nosso subconciente. E ao mais leve chamado do coração, afloram-nos aos lábios, num quase automatismo:

"Descansem o meu leito derradeiro

$\mathrm{Na}$ floresta dos homens esquecida."

Quem, dentre vós, que me ouvis, desconhecerá êstes dois versos? Não sentis qualquer cousa de extranho au ouvi-los? Por certo que sim. Alvares de Azevedo é quem melhor retrata a face triste da alma estudantina.

Mas a vida da Academia no passado não é feita só de tristezas. Em meio á legião dos que passam os dias com o coração sangrando numa eterna insatisfação, há os que lhe dão também a nota pitoresca. São os que colorem de novas cores o céu sempre farruscoso do lírico byroniano.

São, por exêmplo, de um sabor especial, os acordes da lira gaiata de Bernardo Guimarã os :

"Com grande desgosto dos povos da Arábia

Vieram os bonzos da parte de além:

Comendo presuntos, empadas de trigo,

Sem ter um vintém."

Nada dizem êstes alinhavos poéticos. Sem nexo, sem sentido, dão, no entanto, u'a mostra alegre do vélho convento no passado.

Á medida que vimos vindo para o presente, vêm-nos também surgindo á vista novos monumentos marcadores de fases acadêmicas.

Surge Castro Alves. A cabeleira basta jogada para traz. Fronte altiva. Esguio. Elegante. Don Juan. Eletriza multidões. E' requestado para as reuniões sociais. Torna-se idolo. E acorda em todos os corações brasileiros a sua inata piedade para os que sofrem. Soam as tubas condoreiras anunciando clangorosamente uma nova aurora. E o preto ergue-se do charco em que se arrasta. Vêm para o verso as lúgubres tristezas dos engenhos e senzalas. $\mathrm{E}$ quando implora o poeta, finalmente:

"Senhor Deus dos desgraçados!"

lança nêsse grito a angústia de todos os corações brasileiros. 
Um rosário de outros nomes poderiamos vir debulhando. São tantos, que, para lhe serem cantadas as glórias, seriam necessários compêndios.

Nas suas outras faces a Academia não se mostra menos rica. Basta-nos lembrar que todos os nossos presidentes da República, a exceção de somente dois dêles, formaram aqui, por onde hoje passamos, a sua inteligência e o seu carater. Aqui beberam os ensinamentos que os guiaram nas posições de mando a que se ergueram. E si para a Faculdade não é glória ter tido como seus alunos muitos dos que nos dirigiram, não é mentira que todos contribuiram com um pouquinho do que levaram desta casa para a felicidade da Pátria. Olhados em conjunto, forma mum todo em que as esplêndidas cintilações de algumas inteligências impedem-nos de perceber o apagado de muitas delas.

Em todo o seu trajeto secular a nossa Escola vem lançando no vórtice dos jogos políticos os mais legítimos valores. E si me permitisseis lembrar-vos, prezados ouvintes, o nome do maior dêles, eu vos falaria de Rui.

Aqui êle foi aluno. De nossas cátedras escutou ensinamentos. E mais tarde aqui também pontificou. A “Oração aos moços" ainda ecôa por todos os cantos das nossas salas. Seus ensinamentos ainda nos guiam em muitos passos de nossa vida.

O meio acadêmico era pequeno para o seu tamanho: êle projetou-se na Pátria; esta foi acanhada ainda para conter a sua figura: êle projetou-se na humanidade. Abriu suas asas de candor pela amplidão de ceus internacionais, defendendo o direito, enobrecendo a liberdade. E quando terminou seus vôos, nós o colocámos num pedestal de glórias. Marcou o início e o fim de uma época. Encerrou com a sua vida o saudoso tempo dos sonhos liberais.

Rendamos-lhe culto á memória. Ornemos o pedestal de seu monumento com as flores da gratidão acadêmica. 
Juristas, nós o fizemos quase todos os grandes de nossa terra. Enumerá-los seria fastidioso. A série que os Teixeira de Freitas, Lafayette e Rui encabeçam, é admiravel. São nomes que se alçam com a formação intelectual e moral que lhes deu a Faculdade, para os vastíssimos horizontes do Direito. Toda a Pátria os conhece. Todos os brasileiros rendem-lhes o culto de sua devoção.

Na vida da Escola, entretanto, em nenhuma época se pôs em xeque o seu valor quanto na hora em que vivemos. Não estamos mais na cidade senhorial dos vélhos beirais e das ruas coleantes e estreitas. Sumiram-se os lampeões do romantismo dos nossos primeiros poetas As rótulas e ás mantilahas esconderam-se no tempo. Os moços já não mais dedilham os violões nas serenatas a altas horas. Tornou-os angustiosos, tristes, o imperativo de outros problemas e necessidades.

$\mathrm{O}$ mundo inteiro se confrange em contorsões de ódio. E no tumultuar de toda a humanidade, surgem outros pendões guerreiros, sustentados nas mãos nervosas da mocidade.

Os imperialismos desenham-se nitidamente. Povos se aglomeram em regiões parcas de terras. Povos se empenham na defêsa de imensos territórios.

Legiões famintas esmolejam uma aurora salvadora, erguendo as mãos súplices para os céos borrascosos.

Religiões milenárias tremem nos seus pedestais. Fábricas fumarentas trituram nos agigantados maquinismos vidas que se atiram no redomoinho das necessidades.

A mocidade não poderia ser a mesma. A Faculdade de Direito é um pequeno mundo onde se jogam todos os interesses e onde vivem todos os temperamentos, desde os que se afizeram ao ritmo da época, até os que ainda se sublimam na poesia.

Eis, srs., a causa da agitação presente. Eis por que no momento a mocidade se desorienta, sem achar no passado 
luzes que a guiem no presente. Tateando aqui e ali, ela vai, á cabra-céga, de entre-choque em entre-choque, procurar qualquer cousa de estavel e de definido.

Cabe aos nossos lentes no presente, a exêmplo do que se fez no passado, guiar-nos nessa contingência. Acredito que o farão. Muitos valores, talvês maiores que os do passado, brilham entre êles. Si o não fizerem, entretanto, não conseguirão, como até agora, conter a força do novo pensamento. A mocidade não conhece obstáculos. Quando seus músculos se entezarem, ela arrancará, com a força magnetizadora dos grandes ideais.

Meus senhores.

Um século e sete ânos de vida completa a nossa Escola! Trinta e um ânos a associação que representa os seus alunos!

Um longo passado! Património moral imenso, faz-se mistér que o não desmereçamos no presente e no futuro.

A vós, ilustres mestres, eu peço que sejais, das vossas cátedras, guias firmes e destemerosos. E a vós, colegas meus, que continueis a batalhar pela grandeza da Pátria e pelo bem da humanidade. 